\title{
Pulsed radiofrequency treatment of complex regional pain syndrome: A case series
}

\author{
Vlad Djuric MD
}

\begin{abstract}
V Djuric. Pulsed radiofrequency treatment of complex regional pain syndrome: A case series. Pain Res Manag 2014;19(4):186-190.
\end{abstract}

BACKGROUND: Various forms of sympathetic chain neurolysis (sympathectomy) have, at one time or another, held promise as effective treatment options for complex regional pain syndrome (CRPS). Complications, such as worsening pain and the development of new pain syndromes, have prevented sympathectomy from emerging as a standard intervention. In an effort to avoid poor outcomes associated with neurolysis, pulsed radiofrequency (PRF) has been proposed as a potential treatment alternative for a number of chronic neuropathic pain states, including some forms of CRPS. METHODS: The present report describes three cases in which patients diagnosed with lower extremity CRPS type I obtained substantial and lasting intervals of pain relief following PRF of the lumbar sympathetic chain. Over a period of four years, 14 fluoroscopically guided procedures using PRF lesioning of the lumbar sympathetic chain at L2, L3 and L4 were performed in three individuals with CRPS type I of the lower limb. Outcome measures included pre- and post-treatment self-reported pain and medication requirements.

RESULTS: Substantial pain relief ( $>50 \%$ ) was achieved in $91.7 \%$ of PRF applications at three months and $83.3 \%$ at six months, with some treatments resulting in persistent relief well beyond 12 months. Medication use decreased to a comparable degree, with discontinuation of opiates after all but three treatments.

CONCLUSIONS: PRF lesioning of the lumbar sympathetic chain can be an effective treatment for patients with CRPS type I of the lower extremity, with the potential to provide $\geq 6$ months of substantial pain relief.

Key Words: CRPS; Neurolysis; Pulsed radiofrequency; Sympathectomy

$\mathrm{C}$ omplex regional pain syndrome (CRPS) is a progressive chronic pain disorder characterized by, among other symptoms, intense burning or aching pain, allodynia and sudomotor changes. Specific diagnostic criteria for CRPS (Table 1) were developed by the International Association for the Study of Pain in 1994 (1). Multiple subsequent modifications of these criteria demonstrate an ever-evolving, yet still incomplete, understanding of this complex disorder (2).

Despite many noteworthy gains, treatment of CRPS remains difficult (3). An interdisciplinary and individualized approach is generally recommended (4); however, strong evidence in support of any one specific treatment or treatment combination is lacking. Numerous therapeutic options have been described, but there is very little highquality evidence in the literature to guide treatment (5). In a recent literature review of CRPS, 76 randomized controlled trials were identified, the majority of which focused on the role of sympathetic blockade in both its diagnosis and treatment (6). Inasmuch as sympathetic blocks may confirm what appears to be sympathetically mediated pain and may provide short-term symptom relief in some patients, longterm benefit is unlikely $(7,8)$.

Over the past decade, spinal cord stimulation (SCS) has emerged as a popular treatment for a variety of chronic neuropathic pain states, including CRPS (9). More sophisticated technology and better patient selection criteria have helped to improve SCS treatment outcomes. A recent literature review has reported SCS to be effective in the

\section{Le traitement du syndrome douloureux régional complexe par radiofréquence pulsée : une série de cas}

HISTORIQUE : Diverses formes de neurolyse de la chaîne sympathique (sympathectomie) se sont déjà révélées prometteuses pour le traitement du syndrome douloureux régional complexe (SDRC). En raison de complications, telles que l'aggravation de la douleur et l'apparition de nouveaux syndromes douloureux, la sympathectomie ne s'est jamais généralisée. En vue d'éviter les mauvais résultats cliniques associés à la neurolyse, la radiofréquence pulsée (RFP) a été proposée comme traitement potentiel d'un certain nombre d'états de douleur neuropathique chronique, y compris certaines formes de SDRC.

MÉTHODOLOGIE : Le présent rapport décrit trois cas dans lesquels des patients ayant reçu un diagnostic de SDRC de type I des membres inférieurs ont profité d'un soulagement important et durable de la douleur après une RFP de la chaîne sympathique lombaire. Sur une période de quatre ans, quatorze interventions par fluoroscopie faisant appel à une lésion par RFP de la chaîne sympathique lombaire aux vertèbres L2, L3 et L4 ont été effectuées chez trois personnes ayant une SDRC de type 1 du membre inférieur. Les résultats cliniques incluaient la douleur déclarée avant et après le traitement ainsi que les médicaments utilisés.

RÉSULTATS : Les chercheurs ont constaté un soulagement substantiel de la douleur dans $91,7 \%$ des applications de RFP au bout de trois mois et $83,3 \%$ au bout de six mois, certains traitements donnant lieu à un soulagement bien au-delà de 12 mois. L'utilisation de médicaments a diminué à un degré comparable, et tous les patients, sauf un, ont arrêté de prendre des opiacés après un traitement.

CONCLUSIONS : Les lésions par RFP de la chaîne sympathique lombaire peuvent constituer un traitement efficace chez les patients ayant un SDRC de type I du membre inférieur et peuvent assurer un soulagement important de la douleur pendant au moins six mois.

management of CRPS, with success rates between $60 \%$ and $91 \%(10)$. Although usually embraced by more debilitated, treatment-refractory patients, there are many instances in which this option may not be appealing. In cases in which individuals have less severe forms of the disorder or may not be candidates for SCS, an effective treatment alternative is needed.

Before SCS became a popular treatment for CRPS, particularly in the United States, patients with CRPS temporarily benefitting from sympathetic blocks were considered to be potential candidates for chemical or surgical sympathectomy. The rationale for sympathectomy is based on the controversial presumption that sympathetically maintained pain is a key mechanism in CRPS (11). Unfortunately, complications, such as worsening pain and the development of a 'new' pain syndrome, muted enthusiasm for such procedures $(12,13)$. The majority of adverse outcomes reported with sympathectomy occurred with either injection of neurolytic agents or surgical resection (14). An alternative method of achieving sympathectomy is radiofrequency neurolysis (RFN). Although RFN has a similar degree of efficacy and appears to hold some advantages over chemical and surgical forms of sympathectomy (15), complications such as neuralgia, motor/sensory loss and deafferentation, generally associated with other methods of sympathetic neurolysis, still occur in significant numbers (16). Because complications similar to those encountered with chemical and surgical sympathectomy still occurred, RFN was never embraced as a standard treatment for CRPS.

Rothbart Centre for Pain Care, Toronto, Ontario

Correspondence: Dr Vlad Djuric, Rothbart Centre for Pain Care, 4646 Dufferin Street, Toronto, Ontario M3H 5S4. Telephone 416-512-6407,

fax 416-512-6375 
TABLE 1

International Association for the Study of Pain diagnostic criteria for chronic regional pain syndrome
1. Presence of an initiating event
2. Continuing pain, allodynia or hyperalgesia in which the pain is disproportionate to any known inciting event
3. Evidence at some time of edema, changes in skin blood flow or abnormal sudomotor activity in the region of pain
4. A diagnosis that is excluded by the existence of other conditions that would otherwise account for the degree of pain and dysfunction

A randomized clinical study of radiofrequency lesioning by Slappendel et al (17) suggested that use of lower, nondestructive temperatures could achieve results equal to conventional RFN, potentially avoiding the side effects related to nerve damage. In 1998, Sluijter et al (18) published the first report on pulsed radiofrequency (PRF), concluding that PRF at $42^{\circ} \mathrm{C}$ was superior to conventional RFN for the treatment of radicular pain, attributing the analgesic response to the electromagnetic field generated around the cannula tip. Cosman and Cosman (19) subsequently postulated that the electric field was, in fact, likely responsible for the effect.

The potential for long-duration pain relief without the complications associated with RFN prompted pain interventionalists to explore PRF for a variety of chronic pain states (20). Studies evaluating PRF of the dorsal root ganglion (DRG) (21-23) and medial branch nerves $(24,25)$ for treatment of chronic spinal pain reported favourable outcomes. Treatment of other conditions, such as cervical radicular pain (26), postamputation stump pain (27), shoulder pain (28), groin pain (29) and postsurgical thoracic pain (30), with PRF have been investigated, generally reporting favourable success rates.

PRF appears to be suitable for the management of several neuropathic pain conditions. Furthermore, procedure-related pain is similar to that of most other pain management interventions. Because of the nondestructive temperatures required to perform the procedure, adverse outcomes associated with neurolysis and deafferentation are avoided. Such advantages over conventional methods of RFN would appear to make PRF an attractive treatment alternative for CRPS as well. However, with the exception of one case report describing the successful treatment of a paraplegic patient's lower-extremity CRPS with PRF of the lumbar sympathetic ganglion (31), our literature search failed to identify any studies documenting its use in such an indication.

The current report presents three consecutive cases in which PRF was used to achieve lasting intervals of analgesia in patients diagnosed with lower-extremity CRPS. Patients in the present case series were each diagnosed with CRPS by the referring physician before their initial consultation with us. They were referred to our pain clinic for further treatment. The present case study recounts our initial experience with PRF in this small group. There were no additional patients treated in this manner that were excluded from the case study. Each individual's response to treatment was analyzed retrospectively.

\section{METHODS}

Patients presented to our clinic with a presumptive diagnosis of CRPS. The diagnosis was clinically confirmed using International Association for the Study of Pain diagnostic criteria (Table 1). The patients provided standard written informed consent before initiating treatment. PRF procedures were performed in an office-based setting using local anesthetic and oral sedation as necessary. The patients were positioned prone and prepped in the usual sterile fashion. C-arm fluoroscopic guidance was used to guide cannula placement. A slight modification of the technique described by Sluijter (32) was used. In each case, the procedure was performed on the affected side at the L2, L3 and L4 levels. The aim was to place the cannula electrode as close as possible to the targeted sympathetic ganglion. Ganglion location was based on anatomical studies by Umeda et al (33). At L2, the anterolateral aspect of the vertebra at the junction of the superior two-thirds and inferior one-third of the vertebral body was targeted; at L3, the junction of the upper one-third and lower two-thirds, and at L4 the middle one-third. Cannula position was confirmed in the anteroposterior and oblique views.

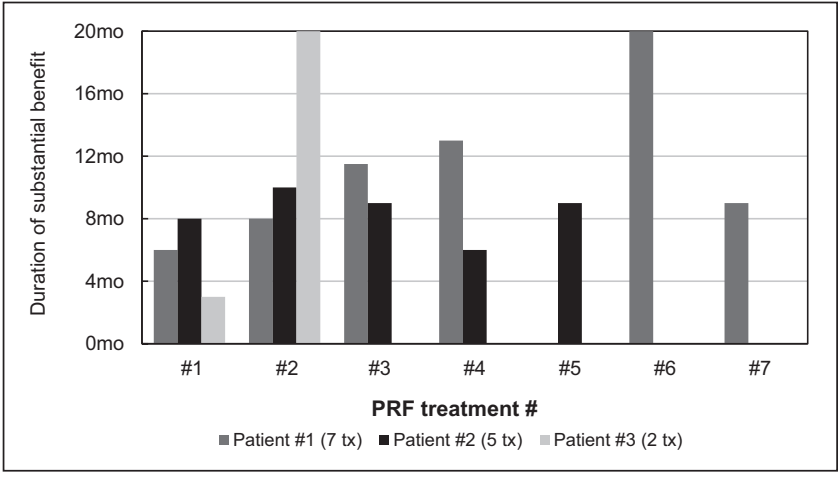

Figure 1) Duration of effectiveness of pulsed radiofrequency (PRF) applications. mo Months; tx Treatments

\section{PRF lesioning}

Under sterile conditions, a radiofrequency electrode $(20 \mathrm{G}, 10 \mathrm{~cm}$ or $15 \mathrm{~cm}$ needle with a curved $10 \mathrm{~mm}$ active tip; Stryker, USA) was advanced to the anticipated location of the ganglion. With exception of skin infiltration with $1 \%$ lidocaine, use of local anesthetic was avoided, particularly around the ganglia. Lesions were created using a Stryker MultiGen radiofrequency generator using the following settings: $2 \mathrm{~Hz}$; $20 \mathrm{~ms}$ pulses; $120 \mathrm{~s}$ to $180 \mathrm{~s}$ duration; $42^{\circ} \mathrm{C}$ temperature limit. Impedance range was between $150 \Omega$ and $450 \Omega$. After the first lesion, the curved cannula was rotated $90^{\circ}$ and a second lesion was created. After another $90^{\circ}$ rotation and/or slight repositioning of the needle tip, a third and, in some cases, a fourth lesion was created.

\section{Outcome measures}

Patients were scheduled for routine follow-up visits following the PRF procedure. They were evaluated for pain relief and medication requirements. Pain level was recorded pre- and postprocedure and at each subsequent follow-up visit. A verbal numerical rating pain scale score ranging from 0 (no pain) to 10 (extreme, suicidal pain) was used to monitor pain. Improvements $>50 \%$ were considered to be substantial. Recurrence of typical pain at intensity $>50 \%$ of pretreatment baseline for two weeks or more marked the end of the benefit period (Figure 1). Pain medication requirements pre- and post-treatment were recorded using a 0 to 4 point scale $(0=$ no medication, $1=$ over-the-counter medications, 2 = nonopioid prescription medications, 3 = as needed opioid prescription medications, $4=$ scheduled opioid prescription medications) (Table 2).

\section{Patient 1}

\section{CASE PRESENTATIONS}

A 48-year-old woman with an unremarkable medical history was injured by a tow motor at work. The trauma resulted in crush injury to her knee and leg, and a large skin avulsion of her left medial calf, which required skin grafting. Although essentially full function of the limb was eventually regained, she was left with residual pain, edema and numbness distal to and including the knee. She was diagnosed with CRPS of the left leg. Following the injury, she received multimodal treatment that included nerve blocks, sympathetic blocks, physical therapy and scheduled opioids. These measures generally resulted in modest relief of her symptoms. On initial presentation to our clinic, eight years after the injury, she described stabbing pain localizing to the medial knee with aching and burning dysesthesias 
TABLE 2

Medication requirements pre- and post-pulsed radiofrequency applications

\begin{tabular}{|c|c|c|c|c|c|c|}
\hline \multirow[b]{2}{*}{ Treatment number } & \multicolumn{2}{|c|}{ Patient 1} & \multicolumn{2}{|c|}{ Patient 2} & \multicolumn{2}{|c|}{ Patient 3} \\
\hline & Pre & Post & Pre & Post & Pre & Post \\
\hline 1 & 4 & 0 & 2 & 0 & 4 & 3 \\
\hline 2 & 0 & 0 & 2 & 0 & 4 & 1 \\
\hline 4 & 3 & 0 & 3 & 0 & & \\
\hline 5 & 3 & 3 & 3 & 3 & & \\
\hline 6 & 3 & 0 & & & & \\
\hline
\end{tabular}

0 = No medication; 1 = Over-the-counter medications; 2 = Nonopioid prescription medications; 3 = As-needed opioid prescription medications; 4 = Scheduled opioid prescription medications

distally. She remained opioid dependent. Physical examination of the left lower extremity revealed well-healed scars of the medial leg, minimal edema and allodynia.

Three sequential lumbar sympathetic blocks performed in our clinic each resulted in a $75 \%$ to $100 \%$ reduction of pain and a concomitant improvement of limb function. However, within one week of each block, her symptoms would begin to recur and gradually return to baseline.

The patient was offered a novel, 'investigational' treatment - PRF of the lumbar sympathetic chain. She was receptive to the proposal. With PRF, pre- and postprocedural pain scores were similar to those following standard sympathetic blocks. The duration of benefit, however, was markedly longer. The first PRF achieved $>6$ months of benefit, with near-complete to complete pain relief and no need for pharmacotherapy. Subsequent PRF applications resulted in similar degrees of benefit ranging from zero to 20 months in duration. After each successful intervention (six of seven attempts) the patient was able to discontinue all medications and reported gradual return to normal activity and exercise tolerance.

\section{Patient 2}

A 39-year-old woman sustained a severe sprain injury to her left knee and a torn lateral meniscus while lifting a patient at work. Following an uneventful arthroscopic repair of the meniscus, she developed persistent pain, swelling, erythema, dysesthesias and hyperalgesia in the injured limb. She was diagnosed with CRPS. Over a period of six months, she underwent a series of monthly sympathetic blocks, each of which relieved her symptoms for approximately two weeks.

Two years after the original injury, she presented to our clinic with complaints of stabbing, nonradiating pain involving the left knee. Her symptoms were aggravated by increased activity and cold weather, and improved when wearing an elastic sleeve on the knee. Physical examination revealed a limb that was cool to touch distally, with allodynia, hyperesthesia and mottling of the skin.

Sympathetic blocks resulted in temporary, complete to near-complete pain relief, lasting an average of two to three weeks. Because of the patient's complaints of 'nonsympathetic' knee pain and history of meniscal tear, intra-articular injections to the left knee were given concomitantly on two occasions. There was no appreciable difference in degree or duration of pain relief with the additional intra-articular injection.

As with patient 1 , this patient was also offered PRF of the lumbar sympathetic chain. Immediately following the procedure, there was complete pain relief and dramatic warming of the left leg. The first PRF resulted in eight months of substantial relief. The procedure was repeated on four subsequent occasions, with duration of benefit ranging from eight to 10 months. With the exception of the last intervention, medication use decreased significantly following each PRF procedure (Table 2).

\section{Patient 3}

A 31-year-old man experienced chronic left leg pain following a crush injury to his left foot and ankle. The injury occurred when a stack of food crates fell on his leg at work. Initially the patient remained ambulatory, but after a period of seven to 10 days, the pain intensified to such a degree that he was no longer able to bear weight on the injured leg. One year after the injury, he presented to our clinic on crutches, complaining of severe pain, hyperhidrosis and a cold sensation involving the left foot and ankle. Physical examination revealed a cool left foot and ankle, mottled skin, hyperhidrosis distal to the knee, diffuse tenderness to palpation and hair loss involving the distal left leg and foot. Magnetic resonance imaging of the ankle revealed injury of the lateral ankle ligaments. Thermography confirmed a significant reduction of left leg temperature compared with the right.

The patient was diagnosed with CRPS and treatment, which included physical therapy and lumbar sympathetic blocks, was initiated. Immediately after the first anesthetic sympathetic block, the pain completely resolved; the foot became hyperemic and very warm. However, within two days, his symptoms started to recur, returning to baseline within one week. Although there was an initial improvement in weight-bearing tolerance and mobility, by the end of the week he was back on crutches. Repeat sympathetic blocks resulted in increased duration of benefit, but only to a maximum of two weeks.

PRF of the lumbar sympathetic chain was performed on two occasions. After the first treatment, he experienced partial resolution of symptoms for three months. During this time, he was able to walk using a cane instead of crutches, but continued to experience pain localizing to the ankle with increased ambulation. Repeat PRF performed three months after the first treatment resulted in $>80 \%$ pain relief based on a numerical rating pain scale. He no longer required a gait assist device. After a course of physical therapy and work conditioning, he returned to his original job duties. Three months later, he reported complete resolution of his CRPS symptoms. Shortly thereafter he moved and was lost to follow-up. Consequently, only 10 months of benefit was reported. However, the patient contacted the office several years later to inform us that he was still pain free and had never experienced a recurrence of his original CRPS symptoms.

\section{DISCUSSION}

The present small case series is a retrospective analysis of our initial experience with PRF of the lumbar sympathetic chain. It is a summary of the responses of three consecutive patients treated in this manner during the study interval. On all but one occasion, the patients' symptoms were positively impacted. A substantially longer interval of relief was achieved than with standard sympathetic blocks using local anesthetic alone (Figure 1). On all but two occasions, medication requirements decreased (Table 2). Bearing in mind the limitations inherent to such a small sampling of patients, the present case series suggests that PRF of the lumbar sympathetic ganglia may be an effective means of alleviating pain and disability stemming from lower extremity CRPS.

In the course of treating these individuals, several interesting observations were made. Despite our attempts to perform the procedure in a consistent manner, duration of response was highly variable (Table 2). This inconsistency in patient response is not uncommon with both RFN $(34,35)$ and PRF (36) of the DRG. It may be attributed, at least in 
part, to variability of electrode proximity to the DRG during lesioning (37). In the present case series, one major challenge was localizing the targeted sympathetic ganglia. Based on anatomical dissections performed by Murata et al (38), the lumbar sympathetic ganglia and rami communicantes are not distributed segmentally. Their location along the vertebral body varies from one segment to the next, as well as from one patient to another due to rather common anomalies of lumbar sympathetic chain anatomy (39). Cannula placement must, therefore, be approximated. Compared with PRF of the DRG, where target location is more predictable and motor/sensory stimulation can be used to assist in cannula positioning, ideal cannula placement for lesioning of the lumbar sympathetic ganglia is much more challenging. Use of sensory and/or motor stimulation to assist with cannula approximation is not helpful when lesioning the sympathetic ganglia.

During some of our early PRF procedures, we found that patients would occasionally report an acute warming of the limb, usually within seconds of initiating the lesioning. We suspect that rapid limb warming was due to the cannula tip being very near or within the sympathetic ganglion itself, and that this was likely the optimal position for lesioning. With future interventions we attempted to use this observation to our advantage in a trial-and-error manner in an effort to improve outcomes. Before lesioning for the full $120 \mathrm{~s}$ to $180 \mathrm{~s}$ duration, we would perform short-duration trial lesions for $20 \mathrm{~s}$ to $30 \mathrm{~s}$ intervals in several locations, searching for the 'sweet spot'. This method of guiding cannula tip placement was marginally effective. Multiple needle tip adjustments were usually necessary, making it a rather arduous process. The technique was only possible as long as no anesthetic was infiltrated around the ganglion before lesioning. Overall reproducibility using this technique remained poor. Furthermore, although treatments using the technique tended to result in a more lasting analgesic response, this effect was not consistently observed.

In the past decade, pain interventionalists faced a similar challenge when attempting to use a single RF cannula to treat sacroiliac joint (SIJ) pain. As with the lumbar sympathetic ganglia, the variable course of nerves innervating the SIJ made their lesioning unpredictable. A more reliable method of addressing the sacral lateral branches was needed. In 2007, a prospective, open-label study evaluating the efficacy of bipolar radiofrequency ablation of sacral lateral branches

\section{REFERENCES}

1. Stanton-Hicks M, Janig W, Hassenbusch S, Haddox JD, Boas R, Wilson P. Reflex sympathetic dystrophy: Changing concepts and taxonomy. Pain 1995;63:127-33.

2. Harden RN, Bruehl S, Stanton-Hicks M, Wilson PR. Proposed new diagnostic criteria for complex regional pain syndrome. Pain Med 2007;8:326-31.

3. Stanton-Hicks M, Baron R, Boas R, et al. Complex regional pain syndromes: Guidelines for therapy. Clin J Pain 1998;14:155-66.

4. Burton AW, Bruehl S, Harden RN. Current diagnosis and therapy of complex regional pain syndrome: Refining diagnostic criteria and therapeutic options. Expert Rev Neurotherapeut 2005;5:643-51.

5. Tran de QH, Duong S, Bertini P, Finlayson RJ. Treatment of complex regional pain syndrome: A review of the evidence. Can J Anaesth 2010;57:149-66.

6. Albazaz R, Wong YT, Homer-Vanniasinkam S. Complex regional pain syndrome: A review. Ann Vasc Surg 2008;22:297-306.

7. Price DD, Long S, Wilsey B, Rafi A. Analysis of peak magnitude and duration of analgesia produced by local anesthetics injected into sympathetic ganglia of complex regional pain syndrome patients. Clin J Pain 1998;14:216-26.

8. Cepeda MS, Lau J, Carr DB. Defining the therapeutic role of local anesthetic sympathetic blockade in complex regional pain syndrome: A narrative and systematic review.

Clin J Pain 2002;18:216-33.

9. Turner JA, Loeser JD, Deyo RA, Sanders SB. Spinal cord stimulation for patients with failed back surgery syndrome or complex regional pain syndrome: A systematic review of effectiveness and complications. Pain 2004;108:137-47.

10. Grabow TS, Tella PK, Raja SN. Spinal cord stimulation for complex regional pain syndrome: An evidence-based medicine review of the literature. Clin J Pain 2003;19:371-83. was performed by Burham and Yasui (40). Using two parallel electrodes simultaneously, a continuous heat lesion spanning the region between them could be created. Multiple sacral lateral branch nerves travelling along irregular, branching paths to reach the SIJ could, thus, be more reliably lesioned. The technique has been shown to be a more dependable and efficient manner in which to accomplish SIJ neurolysis. A 'strip lesion' connecting two separated bipolar electrode tips is demonstrated ex vivo for tip spacings as large as $20 \mathrm{~mm}$ (41). PRF lesioning of the sympathetic chain using a bipolar method of may be possible as well. It could potentially resolve current efficiency and reproducibility issues concerning the described technique and may be worthy of further investigation.

Although use of PRF for treatment of chronic pain syndromes is becoming more widespread, outcome studies to support this growing use are lacking (42). The vast majority of publications regarding this modality relate to PRF of the DRG (18-23,26-30). Those studies suggest that $\mathrm{PRF}$ is emerging as a potential alternative to other forms of treatment such as pharmacotherapy, epidural injections, SCS and surgery in certain patients. With only limited evidence supporting its benefits in very challenging chronic pain conditions, PRF remains controversial and continues to elicit skepticism and doubt. As with any therapy of uncertain efficacy, larger prospective trials are needed to evaluate the utility of PRF in chronic pain states such as CRPS. The present study, although limited by its small sample size and retrospective design, highlights the potential benefit of PRF in a difficult and usually intractable condition.

As more personal accounts, such as the present case series, are published and made available for critique and discussion, we can begin to answer some basic questions regarding the treatment: Which patients stand to benefit most? Do benefits consistently outweigh risks? Are the results reproducible? How can the technique be improved?

\section{CONCLUSIONS}

The presented findings suggest that a select group of individuals with less severe forms of lower limb CRPS can be safely treated with PRF. Based on our experience, PRF of the lumbar sympathetic chain can provide lasting pain relief in select patients with CRPS who demonstrate a positive response to sympathetic blockade. Patients treated in this manner may obtain sustained benefit of $\geq 6$ months.

11. Drummond PD. Involvement of the sympathetic nervous system in complex regional pain syndrome. Int J Low Extrem Wounds 2004;3:35-42.

12. Furlan AD, Lui PW, Mailis A. Chemical sympathectomy for neuropathic pain: Does it work? Case report and systematic literature review. Clin J Pain 2001;17:327-36.

13. AbuRahama AF, Robinson PA, Powell M, Bastug D, Boland JP. Sympathectomy for reflex sympathetic dystrophy: Factors affecting outcome. Ann Vasc Surg 1994;8:372-9.

14. Mockus MB, Rutherford RB, Rosales C, Pearce WH. Sympathectomy for causalgia: Patient selection and long-term results. Arch Surg 1987;122:668-72.

15. Manchikanti L. Evidence-based medicine, systematic reviews, and guidelines in interventional pain management: Part 4: Observational studies. Pain Physician 2009;12:73-108.

16. Haynsworth RF, Noe CE. Percutaneous lumbar sympathectomy: A comparison of radiofrequency denervation versus phenol neurolysis. Anesthesiology 1991;74:450-63.

17. Slappendel R, Crul BJ, Braak GJ, et al. The efficacy of radiofrequency lesioning of the cervical spinal dorsal root ganglion in a double blinded randomized study: No difference between 40 degrees C and 67 degrees C treatments. Pain 1997;73:159-63.

18. Sluijter ME, Cosman ER, Rittman WB, Van Kleef M. The effects of pulsed radiofrequency fields applied to the dorsal ganglia - a preliminary report. Pain Clin 1998;11:109-17.

19. Cosman E Jr, Cosman E Sr. Electrical and thermal field effects in tissue around radiofrequency electrodes. Pain Med 2005;6:405-24

20. Cahana A, Van Zundert J, Macrea L, Van Kleef M, Sluijter M. Pulsed radiofrequency: Current clinical and biological literature available. Pain Med 2006;5:411-23. 
21. Shabat S, Pevsner Y, Folman Y, Gepstein R. Pulsed radiofrequency in the treatment of patients with chronic neuropathic spinal pain. Minim Invasive Neurosurg 2006;49:147-9.

22. Simopoulos TT, Kraemer J, Nagda JV, Aner M, Bajwa ZH. Response to pulsed and continuous radiofrequency lesioning of the dorsal root ganglion and segmental nerves in patients with chronic lumbar radicular pain. Pain Physician 2008;11:137-44.

23. Van Wiljk RM, Geurts JW, Wynne HJ. Long-lasting analgesic effect of radiofrequency treatment of the lumbar dorsal root ganglion. J Neurosurg 2001;94(Suppl 2):227-31.

24. Mikeladze G, Espinal R, Finnegan R, Routon J, Martin D. Pulsed radiofrequency applications in treatment of chronic zygapophyseal joint pain. Spine J 2003;3:360-2.

25. Lindner R, Sluijter ME, Schleinzer W. Pulsed radiofrequncy treatment of the lumbar medial branch for facet pain: A retrospective analysis. Pain Med 2006;7:435-9.

26. Van Zundert J, Patijn J, Kessels A, Lame I, van Suijlekom H, van Kleef M. Pulsed radiofrequency adjacent to the cervical dorsal root ganglion in chronic cervical radicular pain: A double blind sham controlled randomized clinical trial. Pain 2007;127:173-82.

27. Ramanavarapu V, Simopoulos TT. Pulsed radiofrequency of lumbar dorsal root ganglia for chronic post-amputation stump pain. Pain Physician 2008;11:561-6.

28. Liliang PC, Lu K, Liang CL, Tsai YD, Hsieh CH, Chen HJ. Pulsed radiofrequency lesioning of the suprascapular nerve for chronic shoulder pain: A preliminary report. Pain Med 2009;10:70-5.

29. Cohen SP, Foster A. Pulsed radiofrequency as a treatment for groin pain and orchialgia. Urology 2003;61:645.

30. Cohen SP, Sireci A, Wu CL, Larkin TM, Williams KA, Hurley RW. Pulsed radiofrequency of the dorsal root ganglia superior to pharmacotherapy or pulsed radiofrequency of the intercostal nerves in the treatment of chronic postsurgical thoracic pain. Pain Physician 2006;9:227-36.

31. Akkoc Y, Uyar M, Oncu J, Ozcan Z, Durmaz B. Complex regional pain syndrome in a patient with spinal cord injury: Management with pulsed radiofrequency lumbar sympatholysis. Spinal Cord 2008;46:82-4.

32. Sluijter ME. Radiofrequency. In Radiofrequency: Part 1. Meggen: Flivo Press, 2001:139-48.

33. Umeda S, Arai T, Hatano Y, Horhino K. Cadaver anatomic analysis of the best site for chemical lumbar sympathectomy. Anesth Analg 1987;66:643-6.

34. van Wiljk RMAW, Geurts JWM, Wynne HJ. Long-lasting analgesic effect of radiofrequency treatment of the lumbar dorsal root ganglion. J Neurosurg 2001;94:227-31.

35. Geurts JW, van Wijk RM, Wynne HJ, et al. Radiofrequency lesioning of dorsal root ganglia for chronic lumbosacral radicular pain: A randomized, double-blind, controlled trial. Lancet 2003;361:21-6.

36. Simopoulos TT, Kraemer J, Nagda JV, Aner M, Bajwa ZH. Response to pulsed and continuous radiofrequency of the dorsal root ganglion and segmental nerves in patients with chronic radicular pain. Pain Phys 2008;11:137-44.

37. Martin DC, Simopoulos TT. No consistent methodology used in application of RF to allow valid comparisons. Pain Phys 2008;11:379-80.

38. Murata Y, Takahashi K, Yamagata M, Takahashi Y, Shimada Y, Moriya H. Variations in the number and position of human lumbar sympathetic ganglia and rami communicantes. Clin Anat 2003;16:108-13.

39. Simeone FA. The lumbar sympathetic. Anatomy and surgical implications. Acta Chir Belg 1977;76:17-26.

40. Burnham RS, Yasui Y. An alternate method of radiofrequency neurotomy of the sacroiliac joint: A pilot study of the effect on pain, function, and satisfaction. Reg Anesth Pain Med 2007;32:12-9.

41. Cosman ER Jr, Gonzalez CD. Bipolar radiofrequency lesion geometry: Implications for palisade treatment of sacroiliac joint pain. Pain Pract 2011;11:3-22.

42. Malik K, Benzon HT. Radiofrequency applications to dorsal root ganglia: A literature review. Anesthesiology 2008;109:527-42. 


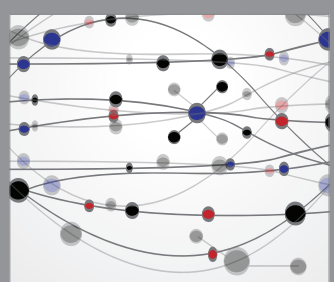

The Scientific World Journal
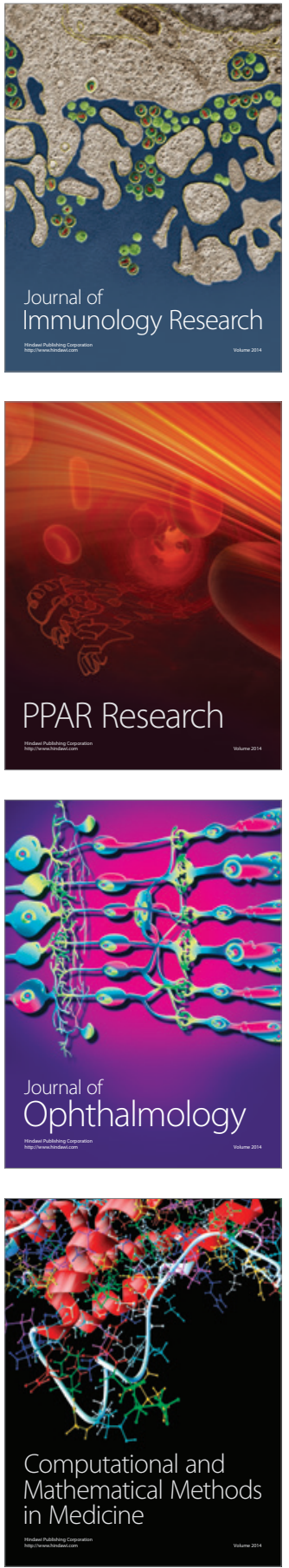

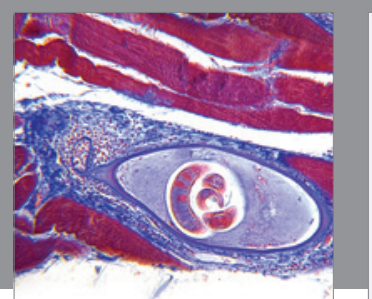

Gastroenterology Research and Practice

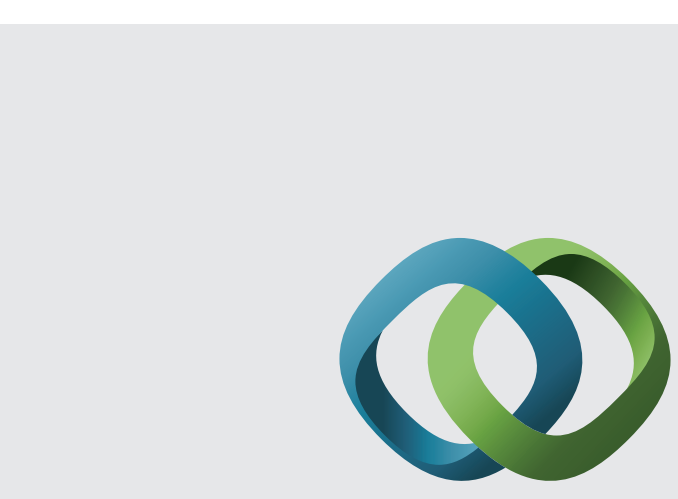

\section{Hindawi}

Submit your manuscripts at

http://www.hindawi.com
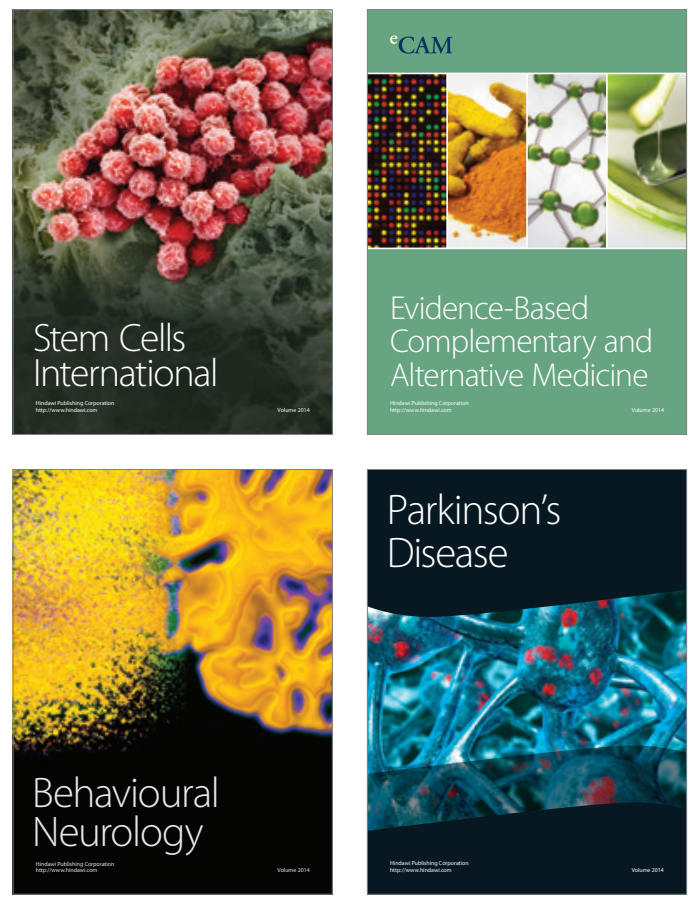
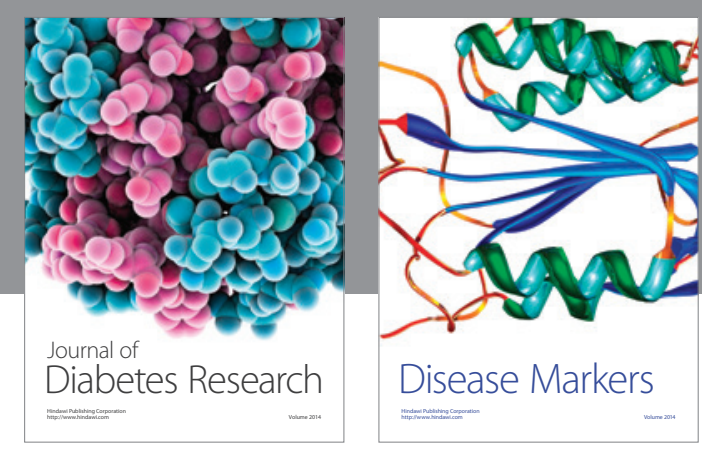

Disease Markers
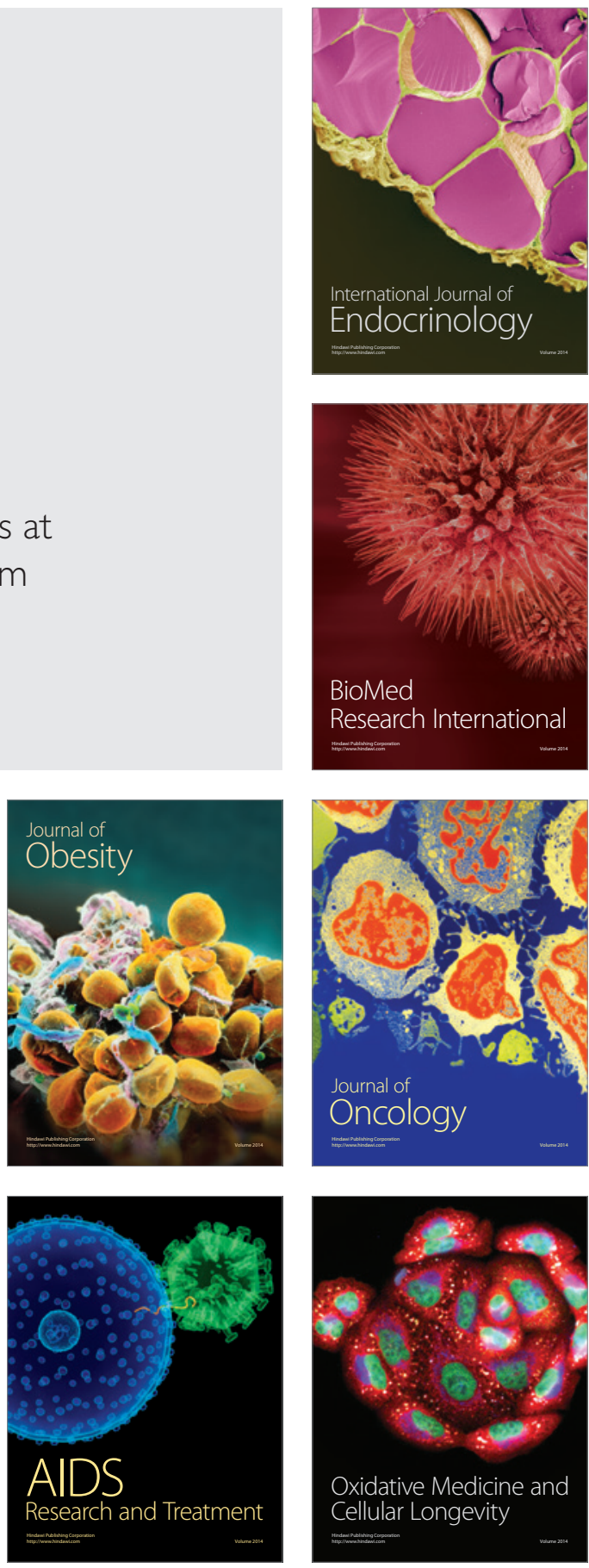